Article

\title{
A Life Cycle Assessment of Silica Sand: Comparing the Beneficiation Processes
}

\author{
Anamarija Grbeš \\ Received: 18 September 2015; Accepted: 18 December 2015; Published: 25 December 2015 \\ Academic Editors: Shinsuke Murakami and Marc A. Rosen \\ Faculty of Mining, Geology and Petroleum Engineering, University of Zagreb, Pierottijeva 6, Zagreb 10000, \\ Croatia; anamarija.grbes@rgn.hr; Tel.: +385-1-5535-901; Fax: +385-1-5535-860
}

\begin{abstract}
Silica sand or quartz sand is a mineral resource with a wide variety of application; glass industry, construction and foundry are the most common examples thereof. The Republic of Croatia has reserves of 40 million tons of silica sand and a long tradition of surface mining and processing. The average annual production of raw silica sand in Croatia in the period from 2006 to 2011 amounted to 150 thousand tons. This paper presents cradle to gate LCA results of three different types of beneficiation techniques: electrostatic separation; flotation; gravity concentration. The aim of this research is to identify and quantify the environmental impacts of the silica sand production, to learn the range of the impacts for different processing methods, as well as to identify the major contributors and focus for further process design development.
\end{abstract}

Keywords: silica; quartz; life cycle assessment; environmental impact; mining; mineral processing

\section{Introduction}

The research was performed from 2009 to 2012 as the final part of the project "Beneficiation of silica sand and environmental impact assessment" [1]. The objective of the analysis refers to general research of environmental impacts in production of silica sand used in glass container manufacture. The results of this LCA are neither intended nor shall be used for decision making or comparative assertions. The aim of the research presented herein was to identify and quantify the environmental impacts of the silica sand production, to learn the range of the impacts for different processing methods, as well as to identify the major contributors and focus on further process design development.

Silica sand or quartz sand is a mineral resource with a wide variety of application; glass industry, construction and foundry are the most common example thereof. The Republic of Croatia has reserves of 40 million tons of silica sand and long tradition of surface mining and processing. The average annual production of raw silica sand in Croatia in the period from 1997 to 2011 [2] amount to about 150 thousand tons.

Raw silica sand deposits are excavated in open pit mines. The method includes topsoil removal and sand excavation. Topsoil is normally made of soil and gangue minerals such as clay, feldspar, muscovite, heavy minerals and/or carbonates [3]. These minerals, depending on the origin of a deposit, are usually found in raw silica sand. In terms of exploitation of silica sand for industrial purposes, it is necessary to remove gangue minerals from excavated topsoil, which is done in a processing plant. The complexity of gangue mineral removal and the possibility to achieve a concentrate with a required chemical composition (95\% or higher silica content) as well as the size and, in some cases, shape of grains are all factors which play a major role in deciding on the intended use of silica (glass or chemical industry, sandblasting, foundry, construction and civil engineering, filtration, agriculture, etc.) [4]. 


\section{Experimental Section}

For the purpose of the research, eight alternatives to the glass grade silica sand production process are designed. The process designs are based on the project solutions of [5-7] and the environmental impact studies performed by [8,9]. An equipment and machinery database is generated for the sake of the design and material flow analysis. The designed inputs and outputs in production processes are checked for consistency with current industry data (2012). The life cycle assessment is conducted using SimaPro software and the LCIA is performed using the ReCiPe Midpoint and Endpoint method (Hierachist/European average) [10]. The functional unit of the analysis is a ton of glass grade silica sand. All calculations are made based on an annual input of $150000 \mathrm{t}$ of raw silica sand. This assumption is taken from the actual mining project of the plant "Pješčara Jerovec" and because it corresponded to annual production in Croatia [2].

The alternatives are named as follows: 1-Electrostatic/dry; 2-Basic/wet; 3-Basic/dry; 4-Flotation/wet; 5-Flotation/dry; 6-Gravity/wet; 7-Gravity/dry; 8-Simulation. During the research period (2009-2012), the glass-grade silica sand production in Croatia corresponded to alternatives 2-3 (basic processing by sizing and washing) and 6-7 (gravity concentration). Electrostatic separation was considered at the design level but has never been installed while flotation was abandoned because of plant destruction in the Homeland War (1991-1995).

What the analysed alternatives have in common is the mining and basic processing operation. The main assumptions for the first seven alternatives were as follows: surface mining using bulldozers; transportation from a mining site to the processing plant $(3 \mathrm{~km})$ by dumpers; then washing and sizing in the processing plant which included sieve washing, attrition scrubbing, hydro-cyclone classifying and dewatering (Figure 1).

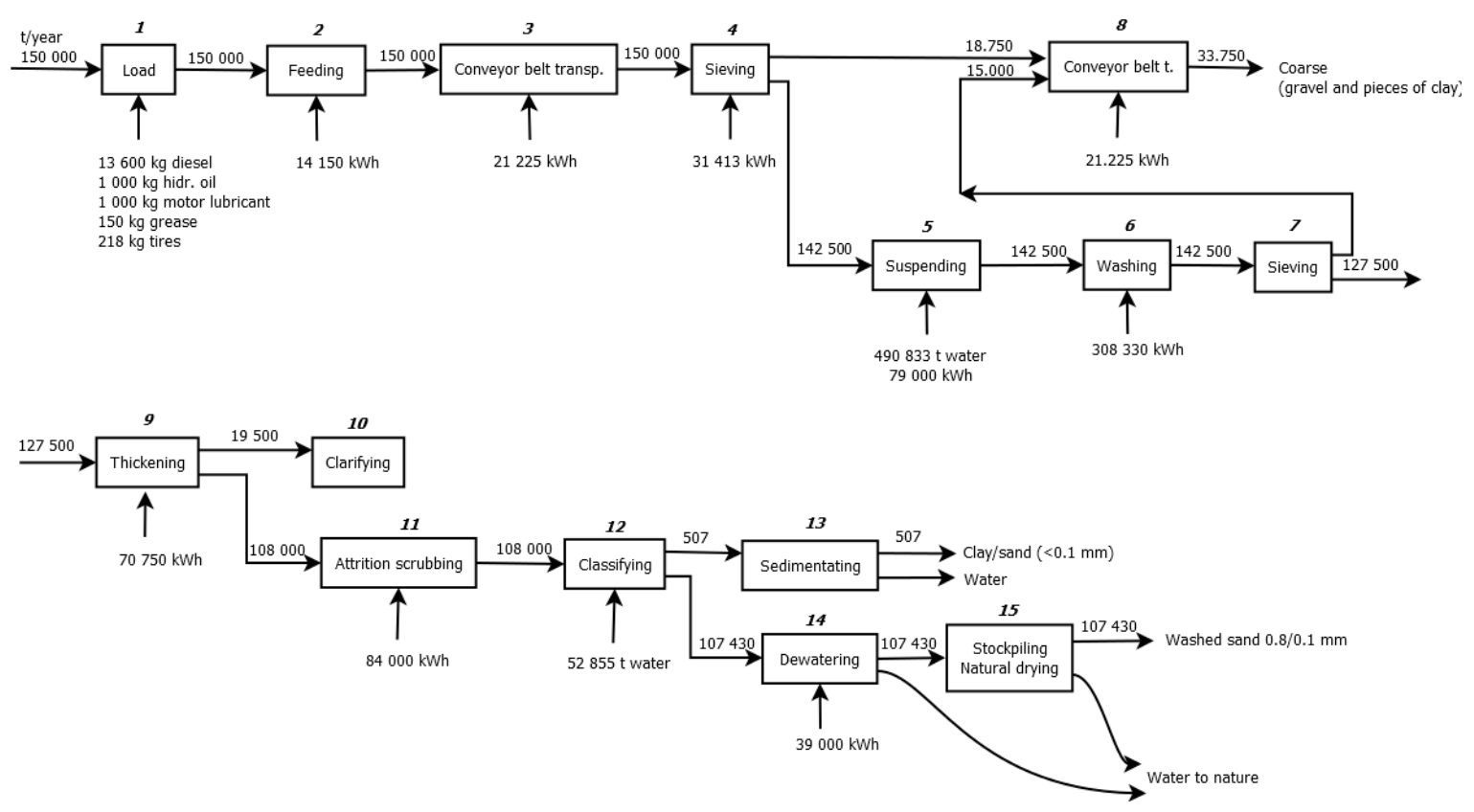

Figure 1. Silica sand washing and sizing (Subsystem A).

The difference between the alternatives reflected in the concentration/separation operations that followed the basic (initial) processing: electrostatic and magnetic separation; flotation; gravity concentration (Figures 2-4). 


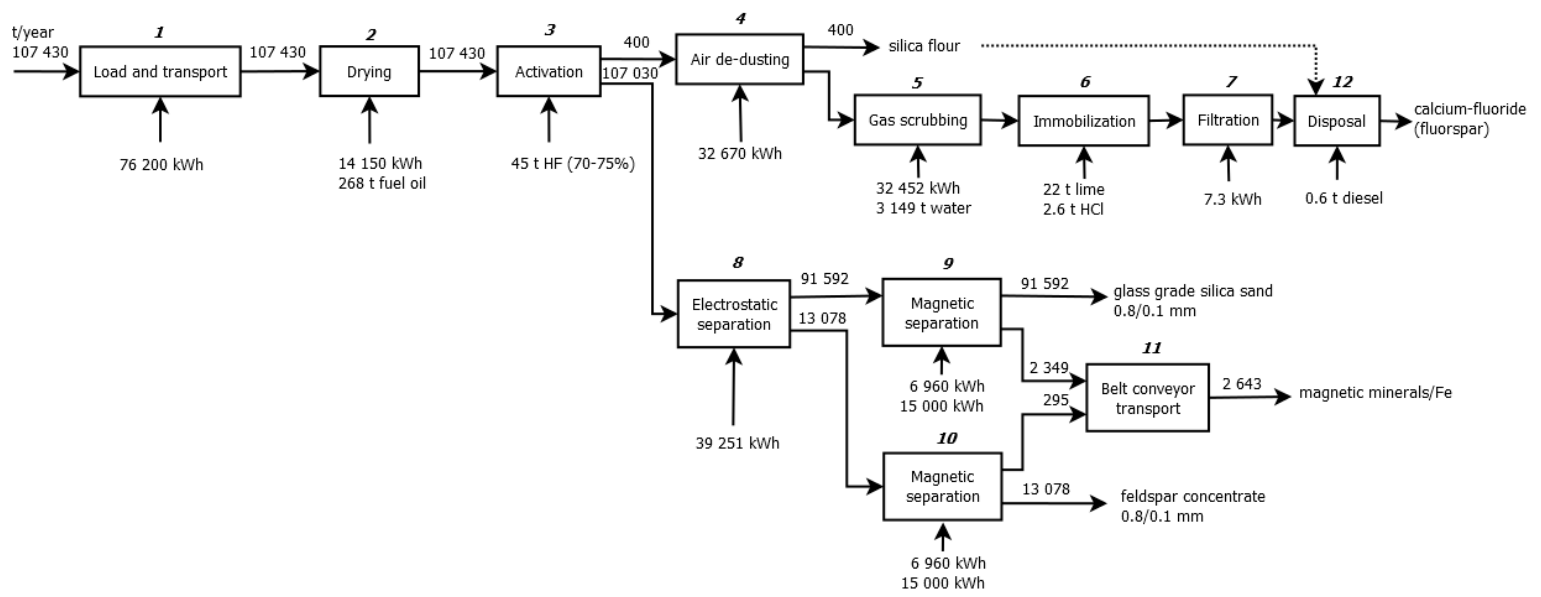

Figure 2. Electrostatic and magnetic concentration/separation of washed silica sand (Subsystem B1).

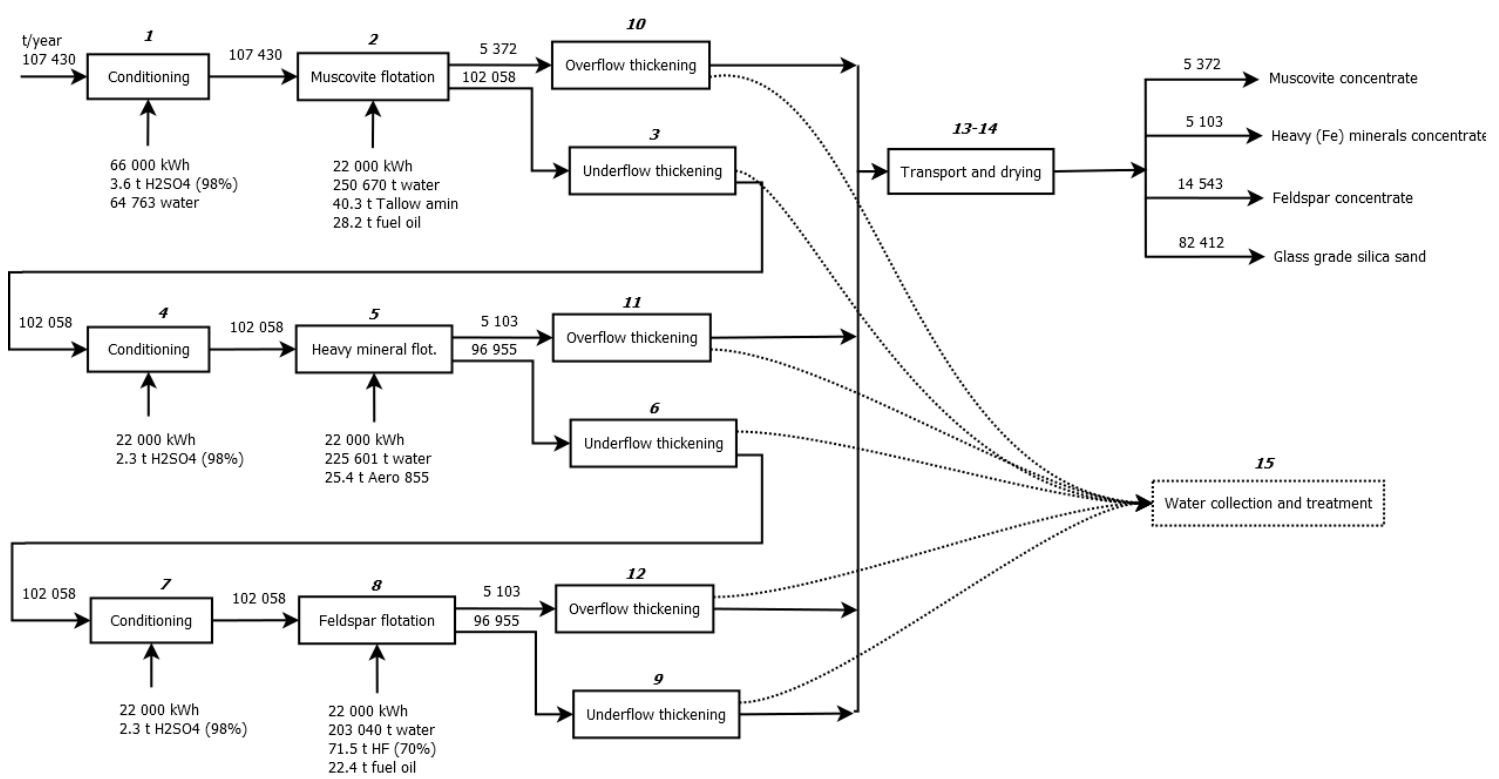

Figure 3. Flotation of washed silica sand (Subsystem B2).

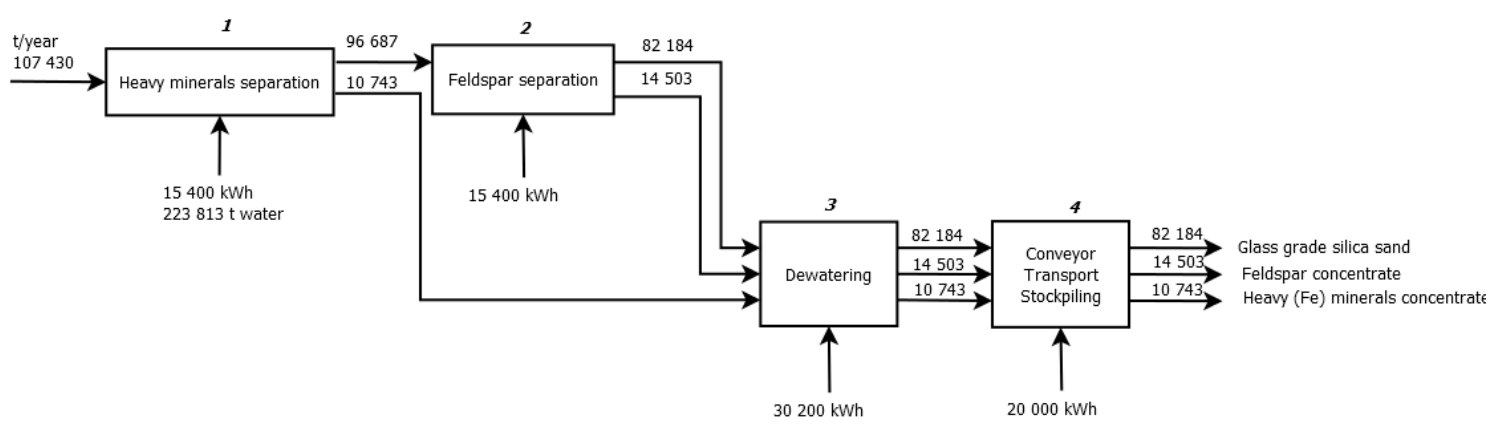

Figure 4. Gravity concentration of washed silica sand (Subsystem B3).

Table 1 shows the structure of the analysed systems. Detailed calculations of the unit processes with respect to each subsystem are presented in the Supplementary 1. 
Table 1. Unit processes included in the analysed systems (Alternatives).

\begin{tabular}{|c|c|c|c|c|c|}
\hline Subsystem & $\begin{array}{l}A \text { Washing } \\
\text { and Sizing }\end{array}$ & $\begin{array}{l}\text { B1 Electrostatic and } \\
\text { Magnetic Conc. }\end{array}$ & B2 Flotation & $\begin{array}{c}\text { B3 Gravity } \\
\text { Concentration }\end{array}$ & Transport \\
\hline \multicolumn{6}{|l|}{ Alternative } \\
\hline 1-Electrostatic/dry & A.1-A.15 & B1.1-B1.12 & & & \\
\hline 2-Basic/wet & A.1-A.15 & & & & \\
\hline 3-Basic/dry & A.1-A.15 & B1.1, B1.2 & & & \\
\hline 4-Flotation/wet & A.1-A.15 & & B2.1-B2.15 & & By truck $100 \mathrm{~km}$ ** \\
\hline 5-Flotation/dry & A.1-A.15 & $B 1, B 2$ * & B2.1-B2.15 & & \\
\hline 6-Gravity/wet & A.1-A.15 & & & B3.1-B3.4 & \\
\hline 7-Gravity/dry & A.1-A.15 & $B 1, B 2$ * & & B3.1-B3.4 & \\
\hline 8-Simulation & \multicolumn{4}{|c|}{ Sand, at mine (Ecoinvent data) } & By train $700 \mathrm{~km}^{* * *}$ \\
\hline
\end{tabular}

Concerning assumptions on water consumption, there was an important difference between the flotation and gravity concentration alternative: with regard to flotation, it is assumed that the process water is collected and re-circulated whereas, considering the gravity concentration, water is taken from the river and returned into the river downstream after the sedimentation. The final assumptions depend on whether the product is sold wet and then dried in a glass factory or is dried and then transported to a glass factory. The alternatives marked "wet" included as follows: road transportation of wet silica sand ( $\mathrm{w}=6 \%$ ) by lorry (truck) for a transporting distance of $100 \mathrm{~km}$; drying in a glass plant using waste heat. The alternatives marked "dry" encompassed as follows: drying in a processing plant; road transportation of dried silica sand $(\mathrm{w}=1 \%)$ by lorry for a transporting distance of $100 \mathrm{~km}$. In the time of the research it was unclear whether the production would continue in the plant that was located about $50 \mathrm{~km}$ from the glass factory, or it would be relocated to the other exploitation site that was about $100 \mathrm{~km}$ distant. So, to be on the safe side, transport distance of the $100 \mathrm{~km}$ is assumed. The simulation alternative involved surface mining and mineral processing outside Croatia and sand import by train for a distance of $700 \mathrm{~km}$ which represented the import from the Czech Republic. This assumption is made using EcoInvent data based on data for sand production in Switzerland.

\section{Results and Discussion}

\subsection{Results of Life Cycle Impact Assessment}

The results of impact assessment are unveiled in Tables 2 and 3 as the values of 18 Midpoint indicators and three Endpoint indicators for each alternative.

Among the analysed alternatives, the following ones revealed the slightest impact: " 8 " (simulation based on Ecoinvent data); "2" (silica sand production from high quality raw sand utilizing simple processing techniques such as sizing and washing ); " 3 " (silica sand production from high quality raw sand utilizing simple processing techniques such as sizing and washing plus drying in a rotary drier); " 6 " (silica sand production utilizing processing techniques such as sizing, washing and gravity concentration); " 4 " (silica sand production utilizing processing techniques such as sizing, washing and froth flotation). An intermediate impact was attributed to alternatives " 1 " (silica sand production utilizing processing techniques such as sizing, washing, drying with grain surface conditioning using hydrofluoric acid, and electrostatic separation) and "7" (silica sand production utilizing processing techniques such as sizing, washing, gravity concentration and drying). A major impact was generated by alternative " 5 " (silica sand production utilizing processing techniques such as sizing, washing, flotation and drying). Utilization of fossil fuels and water intensified the impacts to a great extent. 
Table 2. Midpoint indicator results of life cycle impact assessment for eight cradle-to-gate alternatives in silica sand production (ReCiPe Midpoint (H) V1.06/Europe $\mathrm{ReCiPe} \mathrm{H}$ ) per ton of produced silica sand.

\begin{tabular}{|c|c|c|c|c|c|c|c|c|c|c|}
\hline & \multirow{3}{*}{ Impact Category } & \multirow{3}{*}{ Unit } & \multicolumn{8}{|c|}{ Alternative } \\
\hline & & & 1 & 2 & 3 & 4 & 5 & 6 & 7 & 8 \\
\hline & & & Electrost & Basic/w & Basic/d & Flotation/w & Flotation/d & Gravity/w & Gravity/d & Simulation \\
\hline 1 & Climate Change & $\mathrm{kg} \cdot \mathrm{CO} 2 \cdot \mathrm{eq}$ & $5.27 \times 10$ & $3.30 \times 10$ & $4.30 \times 10$ & $4.31 \times 10$ & $7.52 \times 10$ & $4.19 \times 10$ & $5.25 \times 10$ & $2.96 \times 10$ \\
\hline 2 & Ozone Depletion & $\mathrm{kg} \cdot \mathrm{CFC}-11 \cdot \mathrm{eq}$ & $8.14 \times 10^{-6}$ & $4.66 \times 10^{-6}$ & $6.90 \times 10^{-6}$ & $6.23 \times 10^{-6}$ & $1.17 \times 10^{-5}$ & $6.01 \times 10^{-6}$ & $8.30 \times 10^{-6}$ & $4.48 \times 10^{-6}$ \\
\hline 3 & Human Toxicity & $\mathrm{kg} \cdot 1.4-\mathrm{DB} \cdot \mathrm{eq}$ & 5.46 & 1.92 & 2.38 & 4.51 & 5.52 & 4.57 & 5.09 & $7.25 \times 10^{-1}$ \\
\hline 4 & $\begin{array}{l}\text { Photochemical Oxidant } \\
\text { Formation }\end{array}$ & $\mathrm{kg} \cdot \mathrm{NMVOC}$ & $4.26 \times 10^{-1}$ & $3.56 \times 10^{-1}$ & $3.71 \times 10^{-1}$ & $4.44 \times 10^{-1}$ & $6.42 \times 10^{-1}$ & $4.48 \times 10^{-1}$ & $4.63 \times 10^{-1}$ & $5.07 \times 10^{-1}$ \\
\hline 5 & Particulate Matter Formation & $\mathrm{kg} \cdot \mathrm{PM} 10 \cdot \mathrm{eq}$ & $1.33 \times 10^{-1}$ & $9.93 \times 10^{-2}$ & $1.07 \times 10^{-1}$ & $1.37 \times 10^{-1}$ & $1.90 \times 10^{-1}$ & $1.28 \times 10^{-1}$ & $1.36 \times 10^{-1}$ & $1.13 \times 10^{-1}$ \\
\hline 6 & Ionising Radiation & $\mathrm{kg} \cdot \mathrm{U} 235 \cdot \mathrm{eq}$ & 4.23 & 1.47 & 1.73 & 3.96 & 4.59 & 3.62 & 3.93 & 2.27 \\
\hline 7 & Terrestrial Acidification & $\mathrm{kg} \cdot \mathrm{SO} 2 \cdot \mathrm{eq}$ & $3.35 \times 10^{-1}$ & $2.21 \times 10^{-1}$ & $2.51 \times 10^{-1}$ & $3.36 \times 10^{-1}$ & $4.79 \times 10^{-1}$ & $2.81 \times 10^{-1}$ & $3.13 \times 10^{-1}$ & $2.77 \times 10^{-1}$ \\
\hline 8 & Freshwater Eutrophication & $\mathrm{kg} \cdot \mathrm{P} \cdot \mathrm{eq}$ & $7.39 \times 10^{-3}$ & $2.47 \times 10^{-3}$ & $2.83 \times 10^{-3}$ & $6.15 \times 10^{-3}$ & $7.00 \times 10^{-3}$ & $5.08 \times 10^{-3}$ & $5.59 \times 10^{-3}$ & $6.78 \times 10^{-4}$ \\
\hline 9 & Marine Eutrophication & $\mathrm{kg} \cdot \mathrm{N} \cdot \mathrm{eq}$ & $1.59 \times 10^{-2}$ & $1.27 \times 10^{-2}$ & $1.31 \times 10^{-2}$ & $1.66 \times 10^{-2}$ & $2.37 \times 10^{-2}$ & $1.61 \times 10^{-2}$ & $1.65 \times 10^{-2}$ & $1.75 \times 10^{-2}$ \\
\hline 10 & Terrestrial Ecotoxicity & $\mathrm{kg} \cdot 1.4-\mathrm{DB} \cdot \mathrm{eq}$ & $6.87 \times 10^{-3}$ & $2.62 \times 10^{-3}$ & $5.68 \times 10^{-3}$ & $3.28 \times 10^{-3}$ & $9.09 \times 10^{-3}$ & $4.06 \times 10^{-3}$ & $7.22 \times 10^{-3}$ & $8.17 \times 10^{-4}$ \\
\hline 11 & Freshwater Ecotoxicity & $\mathrm{kg} \cdot 1.4-\mathrm{DB} \cdot \mathrm{eq}$ & $1.33 \times 10^{-1}$ & $5.15 \times 10^{-2}$ & $6.46 \times 10^{-2}$ & $1.14 \times 10^{-1}$ & $1.45 \times 10^{-1}$ & $1.07 \times 10^{-1}$ & $1.21 \times 10^{-1}$ & $2.27 \times 10^{-2}$ \\
\hline 12 & Marine Ecotoxicity & $\mathrm{kg} \cdot 1.4-\mathrm{DB} \cdot \mathrm{eq}$ & $1.63 \times 10^{-1}$ & $5.70 \times 10^{-2}$ & $9.05 \times 10^{-2}$ & $1.14 \times 10^{-1}$ & $1.75 \times 10^{-1}$ & $1.14 \times 10^{-1}$ & $1.50 \times 10^{-1}$ & $2.13 \times 10^{-2}$ \\
\hline 13 & Agricultural Land Occupation & $\mathrm{m} 2 \mathrm{a}$ & $4.59 \times 10^{-2}$ & $2.68 \times 10^{-2}$ & $2.81 \times 10^{-2}$ & $9.91 \times 10^{-2}$ & $1.02 \times 10^{-1}$ & $1.05 \times 10^{-1}$ & $1.03 \times 10^{-1}$ & $4.16 \times 10^{-3}$ \\
\hline 14 & Urban Land Occupation & $\mathrm{m} 2 \mathrm{a}$ & $5.61 \times 10^{-1}$ & $4.72 \times 10^{-1}$ & $4.73 \times 10^{-1}$ & $6.22 \times 10^{-1}$ & $6.24 \times 10^{-1}$ & $8.37 \times 10^{-1}$ & $8.27 \times 10^{-1}$ & $2.90 \times 10^{-1}$ \\
\hline 15 & Natural Land Transformation & $\mathrm{m} 2$ & $4.04 \times 10^{-4}$ & $1.29 \times 10^{-4}$ & $1.37 \times 10^{-4}$ & $2.73 \times 10^{-4}$ & $2.99 \times 10^{-4}$ & $7.29 \times 10^{-3}$ & $6.95 \times 10^{-3}$ & $5.54 \times 10^{-3}$ \\
\hline 16 & Water Depletion & $\mathrm{m} 3$ & 1.81 & 1.24 & 5.83 & 5.24 & 5.28 & 3.06 & 3.08 & 1.43 \\
\hline 17 & Metal Depletion & $\mathrm{kg} \cdot \mathrm{Fe} \cdot \mathrm{eq}$ & $1.22 \times 10^{-2}$ & $4.35 \times 10^{-3}$ & $5.31 \times 10^{-3}$ & $1.20 \times 10^{-2}$ & $1.41 \times 10^{-2}$ & $8.48 \times 10^{-1}$ & $8.07 \times 10^{-1}$ & $4.57 \times 10^{-2}$ \\
\hline 18 & Fossil Depletion & $\mathrm{kg} \cdot$ oil· eq & $2.16 \times 10$ & $1.17 \times 10$ & $1.79 \times 10$ & $1.69 \times 10$ & $3.05 \times 10$ & $1.54 \times 10$ & $2.18 \times 10$ & $1.01 \times 10$ \\
\hline
\end{tabular}

Table 3. Endpoint indicator results of life cycle impact assessment for eight cradle-to-gate alternatives in silica sand production (ReCiPe Midpoint (H) V1.06/Europe ReCiPe H) per ton of produced silica sand.

\begin{tabular}{|c|c|c|c|c|c|c|c|c|c|}
\hline \multirow{3}{*}{$\begin{array}{l}\text { Damage } \\
\text { Category }\end{array}$} & \multirow{3}{*}{ Unit } & \multicolumn{8}{|c|}{ Alternative } \\
\hline & & 1 & 2 & 3 & 4 & 5 & 6 & 7 & 8 \\
\hline & & Electrost & Basic/w & Basic/d & Flotation/w & Flotation/d & Gravity/w & Gravity/d & Simulation \\
\hline Human Health & DALY & $1.12 \times 10^{-4}$ & $7.34 \times 10^{-5}$ & $8.97 \times 10^{-5}$ & $9.92 \times 10^{-5}$ & $1.59 \times 10^{-4}$ & $9.53 \times 10^{-5}$ & $1.12 \times 10^{-4}$ & $7.14 \times 10^{-5}$ \\
\hline Ecosystems & species.yr & $4.33 \times 10^{-7}$ & $2.73 \times 10^{-7}$ & $3.53 \times 10^{-7}$ & $3.58 \times 10^{-7}$ & $6.14 \times 10^{-7}$ & $3.63 \times 10^{-7}$ & $4.47 \times 10^{-7}$ & $2.52 \times 10^{-7}$ \\
\hline Resources & $\$$ & 346.30 & 187.25 & 287.42 & 271.54 & 490.54 & 247.22 & 349.74 & 162.69 \\
\hline Human Health & $\mathrm{Pt}$ & 2.23 & 1.46 & 1.78 & 1.97 & 3.14 & 1.89 & 2.23 & 1.42 \\
\hline Ecosystems & $\mathrm{Pt}$ & 0.99 & 0.63 & 0.81 & 0.82 & 1.41 & 0.83 & 1.02 & 0.58 \\
\hline Resources & $\mathrm{Pt}$ & 2.58 & 1.40 & 2.14 & 2.03 & 3.66 & 1.84 & 2.61 & 1.21 \\
\hline Single score & $\mathrm{Pt}$ & 5.80 & 3.48 & 4.73 & 4.82 & 8.21 & 4.57 & 5.87 & 3.21 \\
\hline
\end{tabular}


As shown, among the analysed beneficiation processes (alternatives 1-7), basic processing (sand washing and sizing) generated the smallest impacts. However, its application for glass-grade silica sand production is limited only to chemically very pure raw sand. The same counts for construction and foundry grade products. Depending on the quality of sand, attrition scrubbing is not always required. In such a case, and if raw sand contains a low percentage of dust particles, the sizing could be managed in a dry regime, which requires less energy and water, but does require more extensive dust control.

With more complex processing (electrostatic separation and flotation) implying prevention of emissions of chemicals into the environment, use of petrol based hydrocarbons (fuels and reagents) can be denoted as important environmental impact factors. This cradle-to-gate LCA of glass-grade silica sand indicated fossil fuel use as the major contributor to the impacts. The risk of at least one chemical incident in the lifetime of a plant should be taken into the account. Also, it is unclear whether the assumed recycling extent of process water and chemicals is really achievable or not. In the former case, the flotation technique would produce even the worst environmental impacts.

The applicability of gravity concentration depends on the quality of raw sand, particularly on the density difference between quartz and accompanying gangue minerals and on the process parameter setup which, according to plant engineers, can take much time and patience until the perfect setup is achieved. Gravity concentration definitely appears to be, from the environmental aspect, a technique worthy of discussion as to its further development. It remains to consider whether exploitation of river water and its return to the same watercourse about hundred meters downstream (after sedimentation) would produce worse environmental impacts than could be expected.

Transportation of naturally dried wet sand and drying it in a glass factory using waste heat resulted in a smaller impact as drying it in a processing plant and then transporting it into a glass factory; however, it would be illusory to expect favourable climate conditions throughout the whole year. The drying option based on fuel oil was probably the worst case scenario. Maybe it would be more beneficiary to use, for example, gas as an energy source, which the respective plant has lately been doing. As an improvement in this area, it might be advisable to consider "greener" sources of heat as well as design of a processing or dryer plant in cooperation with large waste heat producers.

\subsection{Contribution Analysis}

In analysed alternatives we can group all unit processes in four groups:

1. Petrol based (fuel and lubricants)

2. Electricity

3. Water

4. Chemicals

In this part the contribution analysis is shown. The tables and details can be found in supplementary material (Appendices 2 and 3 ).

\subsubsection{Production of the Raw Silica Sand in Croatia}

The production of the raw silica sand is based on the work of the building machine (bull-dozer) and transportation of the excavated material by dumper truck. Both types of machines require diesel and lubricating oil. For the lighting of the excavation site, low voltage electricity is used. Analysing the contributions to calculated endpoint impact categories, fuel (and lubricants) are contributing to $99.9 \%$ of human health damage, $92.5 \%$ of damage to ecosystems and $99.9 \%$ to resource damage. Electricity use contributes to less than $0.1 \%$ damage in each category. Damage to ecosystems that follow from land occupation and use is $7.4 \%$. However, this contribution can vary depending the size of the excavation site and area occupied by the mining company.

Obviously, any lowering of the diesel consumption in raw silica production would contribute to lowering the damage to human health, ecosystems and resources. The excavation and transportation 
calculated here use a cyclic regime of work in which part of the time machines are working "empty", returning from the dumping site or manoeuvring. It would be worthwhile to also analyse the continuous regime of excavation and transport.

The production of the raw silica in Croatia is included in alternatives 1-7 because all alternatives are analysed cradle to gate.

\subsubsection{Alternative 1: Sizing and Washing without Drying}

Alternative 1 includes raw silica sand production, transport from the excavation site to the plant, sizing and washing and transport of the material to the glass factory gate. Processes included are using fuel (petrol based), electricity and water. Contributions to endpoint category "human health" for sizing and washing without drying are $46.8 \%$ from petrol based processes, $5.5 \%$ from electricity use and $0.8 \%$ from water use. Contributions to ecosystems damage are 50.7\% from petrol based processes, $5.0 \%$ from electricity use and $0.8 \%$ from water use. Contributions to resources damage are $52.7 \%$ from petrol based processes, $4.3 \%$ from electricity use and $0.6 \%$ from water use. In this alternative, previously described raw silica sand production makes the remaining $46.9 \%, 44.5 \%$ and $42.3 \%$ for the respective endpoint categories. Clearly, the petrol based processes such as material handling and transport from excavation site to the plant and from the plant to the factory gate are mainly contributing to impact categories.

\subsubsection{Alternative 2: Sizing and Washing with Drying}

Alternative 2 includes raw silica sand production, transport from the excavation site to the plant, sizing, washing, drying and transport of the material to the glass factory gate. Processes included are using fuel (petrol based), electricity and water. Contributions to endpoint category "human health" for sizing and washing without drying are $53.4 \%$ from petrol based processes, $4.7 \%$ from electricity use and $0.6 \%$ from water use. Contributions to ecosystems damage are $59.1 \%$ from petrol based processes, $4.0 \%$ from electricity use and $0.6 \%$ from water use. Contributions to resources damage are $51.6 \%$ from petrol based processes, $2.9 \%$ from electricity use and $0.4 \%$ from water use. The remaining $41.3 \%, 36.2 \%$ and $45.0 \%$ for the human health, ecosystems and resources respectively are contribution of the raw silica production.

\subsubsection{Alternative 3: Electrostatic Separation}

Alternative 3 includes raw silica sand production, sizing and washing which are already analysed in Alternative 1. Assuming that the quality of the washed sand is unfit for glass production due to excessive percentage of the feldspar and heavy minerals, beneficiation technique (electrostatic separation/concentration) is applied. Electrostatic concentration of quartz minerals includes pre-treatments such as drying, conditioning the minerals' surface with hydrofluoric fumes and air cleaning in absorption tower. The produced silica sand is transported to the glass factory.

Analysing the contribution of the applied concentration technique to the endpoint impact categories "human health", "ecosystems" and "resources", the petrol based processes contribute with $34.2 \%, 38.5 \%$ and $45.9 \%$; electricity use $5.6 \%, 4.9 \%$ and $3.7 \%$; and the chemicals use with $2.3 \%$; $1.4 \%$ and $1.0 \%$ respectively. The remaining $57.9 \%$ in human health, $55.2 \%$ in ecosystems and $49.3 \%$ in resources category are following from the processes corresponding to Alternative 1 without transport.

\subsubsection{Alternative 4: Flotation without Drying}

Analysing the contribution of the flotation technique to the endpoint impact categories "human health", "ecosystems" and "resources", the petrol based processes contribute with $3.6 \%, 3.9 \%$ and $10.5 \%$; electricity use $2.2 \%, 2.0 \%$ and $1.6 \%$; water use $1.4 \%, 1.6 \%$ and $1.1 \%$; and the chemicals use with $7.0 \%, 5.5 \%$ and $6.9 \%$ respectively. The remaining $85.7 \%$ in human health, $87.0 \%$ in ecosystems and $79.9 \%$ in resources category are following from the processes corresponding to Alternative 1 without transport. 


\subsubsection{Alternative 5: Flotation with Drying}

Analysing the contribution of the flotation technique with drying to the endpoint impact categories "human health", "ecosystems" and "resources", the petrol based processes contribute with $31.8 \%$, $35.6 \%$ and $43.9 \%$; electricity use $2.0 \%, 1.7 \%$ and $1.3 \%$; water use $1.0 \%, 1.0 \%$ and $0.7 \%$; and the chemicals use with $4.9 \%, 3.7 \%$ and $4.3 \%$ respectively. The remaining $60.3 \%$ in human health, $58.0 \%$ in ecosystems and $50.0 \%$ in resources category are following from the processes corresponding to Alternative 1 without transport.

\subsubsection{Alternative 6: Gravity Concentration without Drying}

In this alternative it is assumed that the pulp (solid/fluid mix) is achieved in the washing stage so no additional water was required. Analysing the contribution of the gravity concentration technique to the endpoint impact categories "human health", "ecosystems" and "resources", the petrol based processes contribute with $29.7 \%, 32.9 \%$ and $32.4 \%$; the electricity use $0.8 \%, 0.7 \%$ and $0.6 \%$ respectively. The remaining $59.5 \%$ in human health, $66.4 \%$ in ecosystems and $66.0 \%$ in resources category are following from the processes corresponding to Alternative 1 without transport.

\subsubsection{Alternative 7: Gravity Concentration with Drying}

In this alternative, it is assumed that the pulp (solid/fluid mix) is achieved in the washing stage so no additional water was required. Analysing the contribution of the gravity concentration technique to the endpoint impact categories "human health", 'ecosystems" and "resources", the petrol based processes contribute with $36.1 \%, 40.5 \%$ and $46.0 \%$; the electricity use $1.2 \%, 1.0 \%$ and $0.8 \%$ respectively. The remaining $62.7 \%$ in human health, $58.5 \%$ in ecosystems and $53.3 \%$ in resources category are following from the processes corresponding to Alternative 1 without transport.

\subsubsection{Alternative 8: Simulation}

Alternative 8 includes the Ecoinvent Data for the production of sand in Switzerland and the data for train transport. Diesel use in train transport contributes with $93.8 \%$ to human health damage, $88 \%$ to ecosystems damage and $93.6 \%$ to resources damage. The remaining $6.2 \%, 12 \%$ and $6.4 \%$ in human health, ecosystems and resources damage category are following from the sand production. In sand production, petrol based processes contribute to respective endpoint categories with $80 \%, 40 \%$ and $82.3 \%$; and the electricity use with $18 \%, 9.3 \%$ and $15.6 \%$.

\section{Conclusions}

The presented results of LCA for Croatian glass-grade silica sand are applied to stress the importance of lowering the impact of silica sand at various production stages in various beneficiation processes and to give the recommendations for future process management and design.

Based on the endpoint results for the comparative analysis and the process contribution analysis shown herein, it is possible to conclude that the preference of the presented processing methods is: simulation of the import, basic processing (sizing and washing) without drying, gravity concentration without drying, basic processing with drying included, flotation without drying, electrostatic separation, gravity concentration with drying included and flotation with drying included. The impacts result mainly from the fossil fuel consumption, electricity consumption, use of the chemicals and water use. These are also the main areas to focus on in further process design. Fossil fuel based processes are recognized as the major contributing factor to all endpoint categories. Therefore, in the process development aimed at better environmental performances, it is highly recommended to focus on replacing petrol-based processes and lowering fossil fuel use.

Acknowledgments: The research presented herein was funded by the Croatian Ministry of Science and Technology. The article was published with support of the Institute of LCA Japan and the University of Zagreb. 
Author Contributions: The main contribution of this article is data collection and modelling of the silica sand beneficiation processes in comparable form and offering the insight from the comparison result I am grateful to the anonymous reviewers who contributed with their valuable comments.

Conflicts of Interest: The author declares no conflict of interest.

\section{References}

1. Grbeš, A. Life Cycle Assessment of Silica Sand Exploitation and Processing in Croatia. Ph.D. Thesis, Faculty of Mining, Geology and Petroleum Engineering, University of Zagreb, Zagreb, Croatia, 22 May 2014.

2. MINGO. The Ministry of Economy of the Republic of Croatia. Reserves and Annual Exploitation 1997-2012. Available online: http://www.mingo.hr/public/rudarstvo/Ukupne_rezerve_min_sirovina_97_13.pdf (accessed on 22 December 2015).

3. Tišljar, J. Sedimentologija Klastičnih i Silicijskih Taložina; Institut za geološka istraživanja: Zagreb, Croatia, 2004.

4. EUROSIL. The European Association of Industrial Silica Producers. Available online: http://www.eurosil.eu/ applications.html (accessed on 15 June 2012).

5. Strajher, M.; Bukvić-Strajher, B.; Pećarina, J. Glavni Rudarski Projekt Eksploatacije Kremenog Pijeska na Eksploatacijskom Polju "Branešci", "MAKS-Projekt" d.o.o.; Main Mining Design of Silica Sand Exploitation at Exploitation Field "Branešci": Virovitica, Croatia, 2005; p. 68.

6. Strajher, M.; Bukvić-Strajher, B.; Pećarina, J. Glavni Rudarski Projekt Eksploatacije Kremenog Pijeska na Eksploatacijskom Polju "Novo Selo", "MAKS-Projekt" d.o.o.; Main Mining Design of Silica Sand Exploitation at Exploitation Field "Novo Selo": Virovitica, Croatia, 2005; p. 68.

7. Vujec, S.; Krkalo, E.; Prokopović, S. Glavni Rudarski Projekt Eksploatacije Kvarcnog Pijeska "Vrtlinska" Iznad Nivoa Podzemne Vode (k 120), R-G-N Fakultet; Main Mining Design of Silica Sand Exploitation at Exploitation Field "Vrtlinska" above the Groundwater Level: Zagreb, Croatia, 1987; p. 153.

8. CEMTRA d.o.o. Studija o Utjecaju na Okoliš Eksploatacijskog Polja "Štefanac"; Environmental Impact Study for Exploitation Field "Štefanac": Zagreb, Croatia, 2003; p. 98.

9. SPP d.o.o. Studija o Utjecaju na Okoliš Eksploatacijskog Polja "Vrtlinska"; Environmental Impact Study for Exploitation Field "Vrtlinska": Varaždin, Croatia, 2003; p. 123.

10. ReCiPe. Methodology. Available online: http://www.lcia-recipe.net/ (accessed on 20 October 2013).

(C) 2015 by the author; licensee MDPI, Basel, Switzerland. This article is an open access article distributed under the terms and conditions of the Creative Commons by Attribution (CC-BY) license (http:/ / creativecommons.org/licenses/by/4.0/). 